\title{
Evaluating the performance of the Indian Diabetes Risk Score in
}

\author{
different ethnic groups \\ ${ }^{1}$ UCL Institute of Ophthalmology, 11-43 Bath Street, London, EC1V 9EL \\ ${ }^{2}$ Moorfields Eye Hospital NHS Foundation Trust, London, United Kingdom \\ ${ }^{3}$ Madras Diabetes Research Foundation and Dr.Mohan's Diabetes Specialities Centre, 4 \\ Conran Smith Road, Gopalapuram, Chennai 600 086, India \\ ${ }^{4}$ Institute for Health and Human Development, University of East London, London, UK \\ Corresponding author: Manjula D Nugawela, manjula.nugawela@ucl.ac.uk.
}

Short running title: Performance of Indian Diabetes Risk Score

Word count of the paper: 2825

Word count of the abstract: $296 / 300$

\section{Novelty Statement:}

- Indian Diabetes Risk Score (IDRS) is a non-invasive diabetes risk score that uses only four variables and it has been identified as a cost-effective tool for identifying undiagnosed diabetes among Indians

- This study has shown that IDRS Score has good performance not only among Indians but also in other ethnic groups including Hispanic, Non-Hispanic White, Non-Hispanic Black and other American

- IDRS can be used in mass screening programmes by non-medically trained health care workers and as a self-administered tool among public to help in early diagnosis, management and optimal control of diabetes in India and America

Keywords: Diabetes Risk Scores, Undiagnosed Diabetes, Indian Diabetes Risk Score 
Abstract

\section{Aim}

To evaluate the performance of Madras Diabetes Research Foundation -Indian Diabetes Risk Score (MDRF-IDRS score) in different ethnic groups including Indians, Hispanic, NonHispanic Whites, Non-Hispanic Blacks and other American.

\section{Methods}

The MDRF-IDRS score is calculated based on a risk equation that includes age, waist circumference, family history of diabetes and physical activity. The National Health and Nutrition Examination Survey (NHANES) data on American and Chennai Urban Rural Epidemiology Study data on Indians were used in this study. Study participants aged $\geq 20$ years with and without type 2 diabetes were included. Performance of the MDRF-IDRS score was assessed using sensitivity, specificity, positive predictive value, negative predictive value and the area under the receiver operating characteristic curve measures within each ethnic group. IDRS scores' performance was then compared with existing noninvasive American diabetes risk scores.

\section{Results}

Total number of participants included was 11,035 (2292 Indians and 8743 American). MDRF-IDRS score (cut off $\geq 60$ ) performed well in Indians with an AUC, sensitivity and specificity of $0.73,80.2 \%$ and $57.3 \%$ respectively. MDRF-IDRS score cut off $\geq 70$ had the highest discriminative performance among Hispanic, Non-Hispanic Whites and NonHispanic Blacks with sensitivity and specificity of between $70.1-86.9 \%$ and $61.2-72.2 \%$ respectively. The AUC for American was between 0.77-0.81 with the highest and lowest AUC in Non-Hispanic Black and Non-Hispanic White respectively. With a smaller number of variables, IDRS score showed almost the same performance in predicting diabetes among American compared with the existing non-invasive American diabetes risk score.

\section{Conclusion}

The MDRF-IDRS score performs well among Indians and American including Hispanic, NonHispanic White, Non-Hispanic Black and other American. It can be used as a screening tool 
Page 3 of 45

to help in early diagnosis, management and optimal control of diabetes mainly in mass screening programmes in India and America.

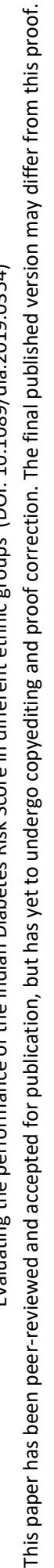


Introduction

Diabetes is a major public health burden in many countries around the world. The number of people with diabetes has risen rapidly over the last few decades and currently, there are around 425 million people with diabetes globally. ${ }^{12}$ In addition to those who have been diagnosed with diabetes, there are a large number of people with undiagnosed diabetes. ${ }^{3}$ The prevalence of undiagnosed diabetes is increasing not only in low-andmiddle income countries but also in developed countries and it can be costly and harmful for the individual as well as for communities and health care systems. ${ }^{4}$ Early detection of people with undiagnosed diabetes is important as it enables them to manage their level of diabetes early on and to have a better quality of life by preventing or delaying the serious life threatening complications of diabetes such as heart disease, stroke, blindness, kidney disease and amputation..$^{5-7}$

The World Health Organization and other health care organizations such as Centres for Disease Control and Prevention and the National Institute for Health and Clinical Excellence (NICE) recommend several different screening tools to identify people with diabetes. ${ }^{589}$ These include risk scoring tools and biochemical tests such as urine glucose, random blood glucose, fasting plasma glucose, glycated haemoglobin (HbA1c) and 75-g oral glucose tolerance test (OGTT) ${ }^{10}$ However, it is difficult to carry out biochemical tests in mass screening programmes as most of them have a lengthy processing time, require patients to fast overnight, require commitment of nursing/laboratory staff, can be expensive to conduct in some areas of the world and some people may not have access to these tests right away. ${ }^{10}$

Whereas, non-invasive risk scoring tools can be used as the first step in mass screening programmes and as a self-administered tool for public. For example, The Diabetes UK encourages people to use their online self-administered non-invasive diabetes risk score in identifying the risk of diabetes. ${ }^{7}$ Using such tools is useful not only for individuals to make informed lifestyle changes but also for the society and for the healthcare systems as it can prevent or delay serious complications of diabetes among the public. 
However, current evidence on the performance of similar scores developed in lowand middle-income countries is rare specially in relation to their applicability in other populations and settings. For example, in 2005, the Madras Diabetes Research Foundation (MDRF) developed the Indian Diabetes Risk score (IDRS) to triage people with undiagnosed diabetes. ${ }^{11-13}$ This was derived from the non-invasive risk factors identified in the Chennai Urban Rural Epidemiology Study (CURES), ${ }^{11}$ which include waist circumference, family history of diabetes, age and level of physical activity. ${ }^{11}$ Compared with other non-invasive diabetes risk scores developed for Indians, ${ }^{14-16}$ IDRS is the most commonly externally validated tool in a large number of studies across India. ${ }^{13}$ 16-27 It has been identified as a cost-effective, simple and easy to use tool mainly in resource restricted settings. According to the MDRF-IDRS model development study by Mohan et al, the sensitivity and specificity of IDRS is $72.5 \%$ and $60.1 \%$ respectively. ${ }^{11}$ Several other studies conducted in different regions of India has shown that the sensitivity and specificity of IDRS in identifying undiagnosed diabetes can vary between $50.8 \%-97.5 \%$ and $17.6 \%-91.7 \%{ }^{11}{ }^{13} 16-27$

Despite these existing studies from India, the performance of MDRF-IDRS score has not yet been evaluated in other settings or among other ethnic groups. MDRF-IDRS score is also likely to be applicable among American as it was initially developed using the risk factors recommended by the American Diabetes Association. ${ }^{11}$ However, its performance among American has not yet been formally evaluated. There are numerous diabetes risk scores available for American but most of them require some form of clinical measurement such as blood pressure level, cholesterol level, fasting plasma glucose level, etc and hence it is difficult to use them in mass screening programmes, ${ }^{28}{ }^{29}$ whereas IDRS score is a non-invasive risk score that requires only four variables. In addition, a substantial percentage of people with undiagnosed diabetes in India $^{30}$ as well as in America ${ }^{31}$ reported to have no contact with a primary care provider. This emphasises the importance of noninvasive diabetes risk scores that can be used in mass screening as well as a selfadministered tool in both settings. Moreover, people with undiagnosed diabetes are likely to be unevenly distributed in different ethnic/racial and socioeconomic groups. ${ }^{32}$ For example, the age-standardized percentage of undiagnosed diabetes cases among Hispanics and non-Hispanic Asian are reported to be higher than all other racial/ethnic 
groups in America. ${ }^{32}$ Hence it is important to assess the performance of risk scores in different ethnic groups separately.

Therefore, in this study, we aimed to assess and compare the MDRF-IDRS scores' performance among Indian and American ethnic groups including Hispanic, Non-Hispanic White, Non-Hispanic Black, and other American. Moreover, we aimed to compare MDRFIDRS score's performance with existing non-invasive American diabetes risk scores.

\section{Methods}

MDRF-IDRS score assigns weights for each risk factor (age, abdominal obesity, physical activity level and family history of diabetes) and generates an aggregated weighted score between 0-100 as shown in Table 1. We used this weighted score in the National Health and Nutrition Examination Survey (NHANES) and Chennai Urban Rural Epidemiology Study (CURES) data to assess MDRF-IDRS scores performance in different ethnic groups including Hispanic, Non-Hispanic White, Non-Hispanic Black, other American and Indians.

Table 1: Indian Diabetes Risk Score (MDRF-IDRS Score)

NHANES is a repeated cross-sectional survey which is performed in 2-year cycles among a nationally representative sample of the US civilian, noninstitutionalized US population. ${ }^{33}$ We used NHANES data for the years of 2003-2006 for adults aged $\geq 20$. NHANES data on the age, ethnicity, family history of diabetes, waist circumference, and level of physical activity were obtained from relevant data files. Average level of physical activity each day was questioned in NHANES by providing study participants with four options to select. The first is "sits during the day and not walk about very much" this option was matched with the IDRS "no exercise and sedentary work" category. The second and third options of NHANES "stand or walk about a lot during the day but do not have to carry or lift things very often" and "lifts light load or has to climb stairs or hills often" were matched with the IDRS "Exercise (regular) or strenuous work" category. The third NHANES physical activity group "do heavy work or carry heavy loads" were matched with the IDRS "Exercise (regular)+ strenuous work" group. Study participants of NHANES were questioned if "any of close relatives that is blood relatives including father, mother, sisters or brothers had diabetes". The answer to this question was "yes/no" and if they answered yes this was 
matched with IDRS "both parents diabetic" category otherwise it was matched with the IDRS score's "No family history" category.

Within the NHANES cohort, people with type 2 diabetes were identified using their selfreported history of diabetes based on the question, "Have you ever been told by a doctor or health professional that you have diabetes or sugar diabetes?" (Answered yes and borderline were considered as having diabetes) OR if they had glycated haemoglobin $(\mathrm{HbA} 1 \mathrm{c}) \geq 6.5 \mathrm{OR}$ if they were taking anti-diabetes medication according to the medication inventory file. People with type 1 diabetes were excluded from the study population. Type 1 diabetes patients were defined as those who have been diagnosed with diabetes before age 30 , currently taking insulin and started taking insulin within one year of the diagnosis.

We also used data from the CURES study, which is an epidemiological study conducted between 2001-2003 among a representative sample of adults (aged $\geq 20$ years) of Chennai, India. ${ }^{34}$ In Phase 1 of this study, the study participants with self-reported type 2 diabetes were identified. Moreover, age and sex matched non-diabetes subjects and all participants with fasting capillary blood glucose of $\geq 110 \mathrm{mg} / \mathrm{dL}$ underwent an oral glucose tolerance test. Those who confirmed having 2-hour plasma glucose levels of $\geq 200 \mathrm{mg} / \mathrm{dL}$ were identified as newly diagnosed diabetes patients. This survey collected data on age, family history of diabetes, waist circumference, and level of physical activity. In this survey physical activity was measured using an estimate for 24-h energy expenditure. ${ }^{34-36}$ This estimate was generated using a questionnaire on the physical activity which included leisure time, household chores, work, sleep, sedentary activities and other common daily activities. The 24-hour energy expenditure was then categorised into vigorous, moderate, mild, and sedentary physical activity levels. We mapped "vigorous" energy expenditure level to "Exercise[regular] +strenuous work" category of IDRS score; "moderate" and "mild" levels into "Exercise [regular] or strenuous work" category of IDRS and "sedentary" physical activity level to "No exercise and sedentary work" category of IDRS score.

Descriptive analysis was carried out to identify the characteristics of the study participants with and without diabetes in each ethnic group. Chi squared test was used to identify any significant difference between the groups. The MDRF-IDRS score's highest performance 
We then reviewed existing literature on non-invasive American diabetes risk scores for identifying undiagnosed type two diabetes. We excluded models developed using nonregression techniques (e.g. neural networks, classification trees, and machine learning) due to the lack of transparency in these non-regression model development techniques especially in relation to reproducibility and validation in external datasets. ${ }^{37} 38 \mathrm{We}$ identified only one non-invasive American diabetes risk score fulfilling this criteria and it is the Bang et $a^{39}$ score with sensitivity of $79 \%$ and specificity of $67 \%$ in detecting undiagnosed diabetes among American. This score was developed using logistic regression modelling and included age, sex, family history of diabetes, history of hypertension, body mass index, and physical activity level were included as variables. In this score, study participants were considered having family history of diabetes if their parents or siblings had diabetes. Physical activity was measured based on their answer (Yes/No) to the question "Are you physically active". IDRS scores' performance was then compared with this non-invasive American diabetes risk score. NHANES survey uses a complex, multistage, probability sampling design to produce a nationally representative data set. Therefore, we used NHANES survey weights to take the NHANES complex sampling design into account during the data analysis. Data management and analysis were performed using Stata 15 (Stata Corp., College Station, Texas, USA).

\section{Results}

There were 11,035 study participants (2,292 Indians and 8743 American) eligible to include in this study and they were aged $\geq 20$, did not have type I diabetes and they had complete data for all the variables considered in IDRS score. Detailed participant flow diagram is given in Appendices (Figure 2 \& Figure 3). The study population characteristics were varied between the ethnic groups (Table 2). Non-Hispanic-White participants had the lowest prevalence of diabetes (9.1\%) whereas Indian participants had the highest prevalence of 
diabetes (15.5\%). The mean age varied between 38.6 - 47.8 years. The mean waist circumference varied between $83.4-98.9 \mathrm{~cm}$. Physical activity level among Indians were relatively low when compared with the other groups, $80.8 \%$ of Indians were in the low physical activity level group whereas in the other ethnic groups $14.7 \%-25.3 \%$ study participants were in the low physical activity group. Indians and Non-Hispanic Black had the lowest $(23.7 \%)$ and highest (54.2\%) prevalence of family history of diabetes respectively.

As shown in Table 3, age, waist circumference, and family history of diabetes were significantly associated with diabetes in all ethnic groups. Study participants with diabetes were older, had higher waist circumference and had higher prevalence of family history compared to those who did not have diabetes and this trend was common in all ethnic groups. There was no significant difference in the gender distribution among American diabetes and non-diabetes study participants. However, the distribution of gender among Indian diabetes and non-diabetes study participants were significantly different $(p=0.02)$, with higher percentage of males in the diabetes group. People with diabetes had lower level of physical activity compared to those who did not have diabetes and this difference was statistically significant in all ethnic groups apart from the Other-American ethnic group.

The MDRF-IDRS score performed well among Indians and American as shown in Figure 1 and Table 4. The AUC for IDRS score among Indians was 0.7345 and the cut off $\geq 60$ had the highest performance with sensitivity and specificity of $80.2 \%$ and $57.3 \%$ respectively. MDRF-IDRS score cut off $\geq 70$ had the highest discriminative performance among Hispanic, Non-Hispanic White and Non-Hispanic Black ethnic groups with sensitivity and specificity ranging between $70.1-86.9 \%$ and $61.2-72.2 \%$ respectively. For other-American, IDRS score $\geq 60$ was identified as the highest performing cut off with sensitivity and specificity of 94.8\% and $48.9 \%$ respectively. The AUC for Hispanic, Non-Hispanic White, Non-Hispanic Black and Other-American ethnicities was $0.7952,0.7749,0.8148$, and 0.7872 respectively. Moreover, MDRF-IDRS score had a high negative predictive value between $0.94-0.98$ for all ethnicities showing that those who get a negative test result for IDRS are highly unlikely to have diabetes. 
As given in Table 5, the comparison of IDRS score with existing American noninvasive score for undiagnosed diabetes showed that IDRS score has almost the same performance as Bang et al $^{39}$ score which uses six risk factors (Age, Gender, Family history of diabetes, self-reported high blood pressure/medication use for hypertension, weight, physical activity level).

Table 2: IDRS variables and diabetes prevalence of the study population by different ethnic group

Table 3: Differences between people with diabetes and people without diabetes by different ethnic group

Figure 1: IDRS AUC for different ethnic groups

Table 4: Discriminative performance of IDRS score for different ethnicities

Table 5: Comparison of IDRS Score's performance with other non-invasive American diabetes risk scores

Discussion

This is the first study to assess MDRF-IDRS score's performance among American and to carry out a comparison of its performance among Indian and American. It has shown that this score performs well not only among Indians but also in among American ethnic groups including Hispanic, Non-Hispanic White, and Non-Hispanic Black. The MDRFIDRS score can be used to identify people with undiagnosed diabetes in mass health screening programmes. This risk score has a high negative predictive value for all ethnicities and therefore it is suitable as a triage tool to rule out those with a negative test result. Those who get positive test results for IDRS can then be prioritised in providing further testing for diabetes to confirm their diabetes status. The current study results are in line with the existing literature on MDRF-IDRS score performance in different regions in India ${ }^{13}{ }^{17-26}$ and almost all studies showed that 60 is the optimal cut off point for the MDRFIDRS score (Table 6). 
When definitions of physical activity and family history were not identical between the datasets and IDRS score, we tried to use the best available variable within each dataset and categorise them in the best possible way to achieve reasonable consistency across datasets and IDRS score. However, the physical activity categories used in IDRS score seems not specific enough to obtain accurate and comparable measurements across different datasets. This may have resulted in the lower specificity of IDRS score identified in the current study as well as in most of the previously conducted studies. ${ }^{111316-27}$

Table 6: Performance of IDRS Score in identifying undiagnosed diabetes according to previously published studies in India

The MDRF IDRS Score was developed using the non-invasive risk factors, recommended by the American Diabetes Association ${ }^{11}$ and may explain the score's high performance in American ethnicities. Comparison of IDRS Score with existing American non-invasive diabetes scores showed that IDRS has almost the same performance as Bang et al $^{39}$ score. Moreover, IDRS score uses only four variables whereas Bang et $\mathrm{al}^{39}$ score uses six variables including self-reported hypertension which could be difficult to obtain accurately in resource restricted settings as people in these settings are less likely to be aware of their blood pressure levels. ${ }^{4041}$

Undiagnosed diabetes is a major public health burden not only in India but also in the United States. In United States in 2017 there were 7.2 million people with undiagnosed diabetes and this represents $23.8 \%$ of people with diabetes. ${ }^{42}$ People with diabetes in the US incur average medical expenditures that are 2.3 times higher than that in the absence of diabetes and the total estimated cost of diagnosed diabetes in 2017 was $\$ 327$ billion. ${ }^{43}$ Most of these medical expenditure are due to the diabetes related complications and comorbidities. $^{44}$ Delayed diagnosis of diabetes can lead to people having more complications and in return this will cause more burden on the health care system. ${ }^{44}$ In India, the economic burden due to diabetes is even higher and it is expected to rise particularly among the economically disadvantaged groups. ${ }^{45}$ Hence early identification of diabetes though screening can have a substantial impact on reducing the costs associated with delayed diagnosis in both settings. 
In addition, using non-invasive diabetes risk assessment tool such as MDRF-IDRS Score has the potential to reduce the cost of diabetes diagnosis by ruling out those who are unlikely to have diabetes. For example, as shown in Appendices (Figure 4 (b)) among 1000 Hispanic, 325 get a positive result and 675 get a negative test result for IDRS score. Due to high negative predictive value of IDRS score further testing for diabetes will only be required in 325 patients. Therefore, MDRF-IDRS score can help prioritise in early diagnosis of diabetes which also facilitates early management and optimal control of diabetes and reduced risk of complications and associated economic burden for the healthcare system and society.

In this study we have shown that IDRS performs well in different settings and in different populations regardless of the differences in population characteristics such as age distribution, physical activity levels, and family history. We've used the same Indian dataset that was used to develop IDRS and this is likely to have slightly overestimated the performance of IDRS among Indians as risk scores tend to perform well in the development data set. ${ }^{3846}$ Despite this limitation of internal validation of IDRS score it has performed well in the external validation carried out using the NHANES dataset providing that it has good performance in different settings and populations. This study included a nationally representative sample of study participants from America and it combined two consecutive NHANES 2-year cycles (2003-2006) creating a large sample and therefore, the results of this study are generalisable to the American population. However, in the NHANES dataset, the family history of diabetes question did not distinguish between one parent or both parent having diabetes and therefore, we allocated 20 points to those who said yes for family history of diabetes. Whereas, ideally according to the MDRF-IDRS score 10 points should be allocated to those having a single parent with diabetes and 20 points to those with both parents having diabetes as shown in Table 1 . The lack of this information from the dataset might have altered IDRS score's performance among American and future studies could investigate this by using an appropriate dataset. 
Conclusion

The Madras Diabetes Research Foundation-Indian Diabetes Risk Score performs well not only among Indians but also among Hispanic, Non-Hispanic White, Non-Hispanic Black and other American. It can be used as a screening tool to help in early diagnosis, management and optimal control of diabetes mainly in mass screening programmes in India and America. 
Reference

1. International Diabetes Federation. IDF Diabetes Atlas, 2017.

2. World Health Organization. Global Report on Diabetes. Geneva, 2016.

3. Joshi SR, Das AK, Vijay VJ, et al. Challenges in diabetes care in India: sheer numbers, lack of awareness and inadequate control. The Journal of the Association of Physicians of India 2008;56:443-50. [published Online First: 2008/10/01]

4. Beagley J, Guariguata L, Weil C, et al. Global estimates of undiagnosed diabetes in adults. Diabetes research and clinical practice 2014;103(2):150-60. doi: 10.1016/j.diabres.2013.11.001 [published Online First: 2013/12/05]

5. World Health Organization. Screening for Type 2 Diabetes - Report of a World Health Organization and International Diabetes Federation meeting World Health Organization, 20, Avenue Appia, 1211 Geneva 27, Switzerland, 2003.

6. Herman WH, Ye W, Griffin SJ, et al. Early Detection and Treatment of Type 2 Diabetes Reduce Cardiovascular Morbidity and Mortality: A Simulation of the Results of the Anglo-Danish-Dutch Study of Intensive Treatment in People With Screen-Detected Diabetes in Primary Care (ADDITION-Europe). Diabetes care 2015;38(8):1449-55. doi: 10.2337/dc14-2459 [published Online First: 2015/05/18]

7. Diabetes UK. Position Statement Early Identification of people with Type 2 diabetes 2015.

8. National Institute for Health and Clinical Excellence. Preventing type 2 diabetes: risk identification and interventions for individuals at high risk NICE public health guidance 38. Piccadilly Plaza, Manchester M1 4BT, 2012.

9. Centres for Disease Control and Prevention. National Diabetes Prevention Program [updated August $2019 . \quad$ Available from: https://www.cdc.gov/diabetes/prevention/index.html. 
10. Echouffo-Tcheugui JB, Ali MK, Griffin SJ, et al. Screening for Type 2 Diabetes and Dysglycemia. Epidemiologic Reviews 2011;33(1):63-87. doi: 10.1093/epirev/mxq020

11. Mohan V, Deepa R, Deepa M, et al. A simplified Indian Diabetes Risk Score for screening for undiagnosed diabetic subjects. The Journal of the Association of Physicians of India 2005;53:759-63. [published Online First: 2005/12/13]

12. Mohan V, Deepa M, Anjana RM, et al. Incidence of diabetes and pre-diabetes in a selected urban south Indian population (CUPS-19). The Journal of the Association of Physicians of India 2008;56:152-7. [published Online First: 2008/08/14]

13. Adhikari P, Pathak R, Kotian S. Validation of the MDRF-Indian Diabetes Risk Score (IDRS) in another south Indian population through the Boloor Diabetes Study (BDS). The Journal of the Association of Physicians of India 2010;58:434-6. [published Online First: 2010/12/03]

14. Ramachandran A, Snehalatha C, Vijay V, et al. Derivation and validation of diabetes risk score for urban Asian Indians. Diabetes research and clinical practice 2005;70(1):6370. doi: 10.1016/j.diabres.2005.02.016 [published Online First: 2005/08/30]

15. Sathish T, Kannan S, Sarma PS, et al. Achutha Menon Centre Diabetes Risk Score: a type 2 diabetes screening tool for primary health care providers in rural India. AsiaPacific journal of public health 2015;27(2):147-54. doi: 10.1177/1010539512454162 [published Online First: 2012/08/07]

16. Oommen AM, Abraham VJ, Sathish T, et al. Performance of the Achutha Menon Centre Diabetes Risk Score in Identifying Prevalent Diabetes in Tamil Nadu, India. Diabetes \& metabolism journal 2017;41(5):386-92. doi: 10.4093/dmj.2017.41.5.386 [published Online First: 2017/11/01]

17. Nandeshwar S, Jamra V, Pal D. Indian Diabetes Risk Score for Screening of Undiagnosed Diabetic Subjects of Bhopal City National Journal of Community Medicine 2010;1(2) 
18. Divyang N. Patel, Maulik C. Shah, Ghanshyam N. Ahir, et al. A study on validity of Indian Diabetes Risk Score (MDRF) for screening of diabetes mellitus among the high risk group (policemen) of diabetes mellitus of bhavnagar city. . Innovative Journal of Medical and Health Science 2012;2:109-11.

19. Stanley JML, Elantamilan D, Mohanasundaram K, et al. Evaluation of Indian diabetic risk score for screening undiagnosed diabetes subjects in the community. Indian Journal of Science and Technology 2012;5

20. Taksande B, Ambade M, Joshi R. External validation of Indian diabetes risk score in a rural community of central India. Journal of Diabetes Mellitus 2012;2:109-13.

21. Sathish T, Kannan S, Sarma SP, et al. Screening performance of diabetes risk scores among Asians and whites in rural Kerala, India. Preventing chronic disease 2013;10:E37. doi: 10.5888/pcd10.120131 [published Online First: 2013/03/23]

22. Bhadoria AS, Kasar PK, Toppo NA. Validation of Indian diabetic risk score in diagnosing type 2 diabetes mellitus against high fasting blood sugar levels among adult population of central India. Biomedical journal 2015;38(4):359-60. doi: 10.4103/2319-4170.143508 [published Online First: 2014/10/31]

23. Ahmed A. Indian Diabetic Risk Score (IDRS), A Screening Tool for Detecting Undiagnosed Diabetes. BMR Medicine 2015;2

24. Najeeb Q, Singh J, Pandey R, et al. A comparative study of fasting, postprandial blood glucose and glycated hemoglobin for diagnosing diabetes mellitus in staff members of MMIMSR, Mullana, Ambala. Medical Journal of $\mathrm{Dr} D Y$ Patil University 2015;8(2):158-64. doi: 10.4103/0975-2870.153145

25. Dudeja P, Singh G, Gadekar T, et al. Performance of Indian Diabetes Risk Score (IDRS) as screening tool for diabetes in an urban slum. Medical journal, Armed Forces India 2017;73(2):123-28. doi: 10.1016/j.mjafi.2016.08.007 [published Online First: 2017/09/20] 
26. Kaushal K, Mahajan A, Parashar A, et al. Validity of Madras Diabetes Research Foundation: Indian Diabetes Risk Score for Screening of Diabetes Mellitus among Adult Population of Urban Field Practice Area, Indira Gandhi Medical College, Shimla, Himachal Pradesh, India. Indian Journal of Endocrinology and Metabolism 2017;21:876-81.

27. Basu S, Millett C, Vijan S, et al. The health system and population health implications of large-scale diabetes screening in India: a microsimulation model of alternative approaches. PLoS medicine 2015;12(5):e1001827; discussion e27. doi: 10.1371/journal.pmed.1001827 [published Online First: 2015/05/21]

28. Collins GS, Mallett S, Omar O, et al. Developing risk prediction models for type 2 diabetes: a systematic review of methodology and reporting. BMC Medicine 2011;9(1):103. doi: 10.1186/1741-7015-9-103

29. Noble D, Mathur R, Dent T, et al. Risk models and scores for type 2 diabetes: systematic review. BMJ 2011;343:d7163. doi: 10.1136/bmj.d7163

30. Prenissl J, Jaacks LM, Mohan V, et al. Variation in health system performance for managing diabetes among states in India: a cross-sectional study of individuals aged 15 to 49 years. BMC Medicine 2019;17(1):92. doi: 10.1186/s12916-019-1325-6

31. Dall TM, Narayan KM, Gillespie KB, et al. Detecting type 2 diabetes and prediabetes among asymptomatic adults in the United States: modeling American Diabetes Association versus US Preventive Services Task Force diabetes screening guidelines. Population health metrics 2014;12:12. doi: 10.1186/1478-7954-12-12 [published Online First: 2014/06/07]

32. Menke A, Casagrande S, Geiss L, et al. Prevalence of and Trends in Diabetes Among Adults in the United States, 1988-2012. JAMA 2015;314(10):1021-29. doi: 10.1001/jama.2015.10029

33. CDC-Centre for Disease Control and Prevention. About the National Health and Nutrition Examination Survey [updated September 15, 2017. Available from: https://www.cdc.gov/nchs/nhanes/about_nhanes.htm. 
34. Deepa M, Pradeepa R, Rema M, et al. The Chennai Urban Rural Epidemiology Study (CURES)--study design and methodology (urban component) (CURES-I). The Journal of the Association of Physicians of India 2003;51:863-70. [published Online First: 2004/01/09]

35. Bharathi AV, Sandhya N, Vaz M. The development \& characteristics of a physical activity questionnaire for epidemiological studies in urban middle class Indians. The Indian journal of medical research 2000;111:95-102. [published Online First: 2000/08/11]

36. Bharathi AV, Kuriyan $\mathrm{R}$, Kurpad AV, et al. Assessment of physical activity using accelerometry, an activity diary, the heart rate method and the Indian migration study questionnaire in south Indian adults. Public health nutrition 2010;13(1):47-53. doi: 10.1017/s1368980009005850 [published Online First: 2009/08/07]

37. Christodoulou E, Ma J, Collins GS, et al. A systematic review shows no performance benefit of machine learning over logistic regression for clinical prediction models. Journal of clinical epidemiology 2019;110:12-22. doi: 10.1016/j.jclinepi.2019.02.004 [published Online First: 2019/02/15]

38. Moons KG, Altman DG, Reitsma JB, et al. Transparent Reporting of a multivariable prediction model for Individual Prognosis or Diagnosis (TRIPOD): explanation and elaboration. Annals of internal medicine 2015;162(1):W1-73. doi: 10.7326/m140698 [published Online First: 2015/01/07]

39. Bang H, Edwards AM, Bomback AS, et al. Development and validation of a patient selfassessment score for diabetes risk. Annals of internal medicine 2009;151(11):77583. doi: 10.7326/0003-4819-151-11-200912010-00005 [published Online First: 2009/12/02]

40. Pilav A, Doder V, Brankovic S. Awareness, Treatment, and control of Hypertension among Adult Population in the Federation of Bosnia and Herzegovina over the Past Decade. Journal of public health research 2014;3(3):323. doi: 10.4081/jphr.2014.323 [published Online First: 2015/01/02] 
41. Prenissl J, Manne-Goehler J, Jaacks LM, et al. Hypertension screening, awareness, treatment, and control in India: A nationally representative cross-sectional study among individuals aged 15 to 49 years. PLoS medicine 2019;16(5):e1002801. doi: 10.1371/journal.pmed.1002801 [published Online First: 2019/05/06]

42. CDC-Centre for Disease Control and Prevention. National Diabetes Statistics Report, 2017 Estimates of Diabetes and Its Burden in the United States National Center for Chronic Disease Prevention and Health Promotion- Division of Diabetes Translation 2017.

43. Economic Costs of Diabetes in the U.S. in 2017. Diabetes Care 2018:dci180007. doi: 10.2337/dci18-0007

44. Li R, Bilik D, Brown MB, et al. Medical costs associated with type 2 diabetes complications and comorbidities. Am J Manag Care 2013;19(5):421-30.

45. Yesudian CAK, Grepstad M, Visintin E, et al. The economic burden of diabetes in India: a review of the literature. Global Health 2014;10:80-80. doi: 10.1186/s12992-0140080-x

46. Steyerberg EW. Clinical Prediction Models - A practical Approach to Development Validation and Updating New York: Springer 2009.

Acknowledgment

This study, within the ORNATE India project, is funded by the GCRF UKRI (MR/P207881/1). The research was supported by the NIHR Biomedical Research Centre at Moorfields Eye Hospital NHS Foundation Trust and UCL Institute of Ophthalmology.

Author Contribution

The study was conceived by GN, SS and MN. The study was designed by the Ornate India grant co-applicants (GN, SS, VM, RR). MN and GN provided the statistical input. MN drafted the manuscript and all authors commented on drafts and approved the final version. 
Table 1: Indian Diabetes Risk Score (MDRF-IDRS Score)

\begin{tabular}{|l|l|}
\hline Particulars & Score \\
\hline Age & 0 \\
$35-49$ & 20 \\
$50+$ & 30 \\
\hline Abdominal obesity & \\
Waist $<80 \mathrm{~cm}$ [female], $<90 \mathrm{~cm}$ [male] & 0 \\
Waist $\geq 80-89 \mathrm{~cm}$ [female], $\geq 90-99 \mathrm{~cm}$ [male] & 10 \\
Waist $\geq 90 \mathrm{~cm}$ [female], $\geq 100 \mathrm{~cm}$ [male] & 20 \\
\hline Physical activity & 0 \\
Exercise [regular] + strenuous work & 0 \\
Exercise [regular] or strenuous work & 20 \\
No exercise and sedentary work & 30 \\
\hline Family history & 10 \\
No family history \\
Either parent & 20 \\
Both parents & 0 \\
\hline Minimum score & 100 \\
\hline Maximum score & 0 \\
\hline
\end{tabular}


Table 2: IDRS variables and diabetes prevalence of the study population by different ethnic group

\begin{tabular}{|c|c|c|c|c|c|}
\hline & \multicolumn{5}{|c|}{ Ethnicity } \\
\hline & $\begin{array}{l}\text { Indian } \\
N=229 \\
2\end{array}$ & $\begin{array}{l}\text { Hispanic } \\
\quad N^{*}=1786 \\
\text { (PS=15,358,20 } \\
\text { 3) }\end{array}$ & $\begin{array}{l}\text { Non-Hispanic } \\
\text { White } \\
\quad N^{*}=4479 \\
\text { (PS=138,673,83 } \\
\text { 2) }\end{array}$ & $\begin{array}{l}\text { Non-Hispanic } \\
\text { Black } \\
N^{*}=1849 \\
(P S=21,575,79 \\
4)\end{array}$ & $\begin{array}{l}\text { Other- } \\
\text { American } \\
N^{*}=629 \\
\text { (PS=16,772,05 } \\
\text { 4) }\end{array}$ \\
\hline $\begin{array}{l}\text { Diabetes } \\
\text { (Type II) }\end{array}$ & $15.5 \%$ & $11.1 \%$ & $9.1 \%$ & $14.3 \%$ & $12.3 \%$ \\
\hline $\begin{array}{l}\text { Mean Age } \\
\text { (years) }\end{array}$ & 39.6 & 38.6 & 47.8 & 43.4 & 42.4 \\
\hline $\begin{array}{l}\text { Mean Waist } \\
\text { Circumferen } \\
\text { ce } \\
\text { (cm) }\end{array}$ & 83.4 & 97.1 & 97.8 & 98.9 & 92.9 \\
\hline $\begin{array}{l}\text { Gender } \\
\text { Male }\end{array}$ & $46.3 \%$ & $52.7 \%$ & $47.9 \%$ & $44.1 \%$ & $46.1 \%$ \\
\hline $\begin{array}{l}\text { Family } \\
\text { History of } \\
\text { Diabetes } \\
\text { Yes }\end{array}$ & $23.7 \%$ & $52.5 \%$ & $43.1 \%$ & $54.2 \%$ & $45.3 \%$ \\
\hline $\begin{array}{l}\text { Level of } \\
\text { Physical } \\
\text { Activity } \\
\text { Low } \\
\text { Moderate } \\
\text { High }\end{array}$ & $\begin{array}{r}80.8 \% \\
17.0 \% \\
2.1 \%\end{array}$ & $\begin{array}{l}14.7 \% \\
71.1 \% \\
14.2 \%\end{array}$ & $\begin{array}{r}23.9 \% \\
68.1 \% \\
8.0 \%\end{array}$ & $\begin{array}{r}25.3 \% \\
67.9 \% \\
6.8 \%\end{array}$ & $\begin{array}{r}22.7 \% \\
70.4 \% \\
6.9 \%\end{array}$ \\
\hline
\end{tabular}

N: CURES dataset total number of individuals sampled using systematic random sampling

$N^{*}$ : NHANES dataset total number of individuals sampled using complex, multistage, probability sampling design

PS: NHANES Survey weight adjusted nationally representative population size 
Page 22 of 45

NOTE: The proportions presented for American ethnicities represent the survey weight adjusted proportion out of the population size for each category 
Table 3: Differences between diabetic and non-diabetic study participants by different ethnic group

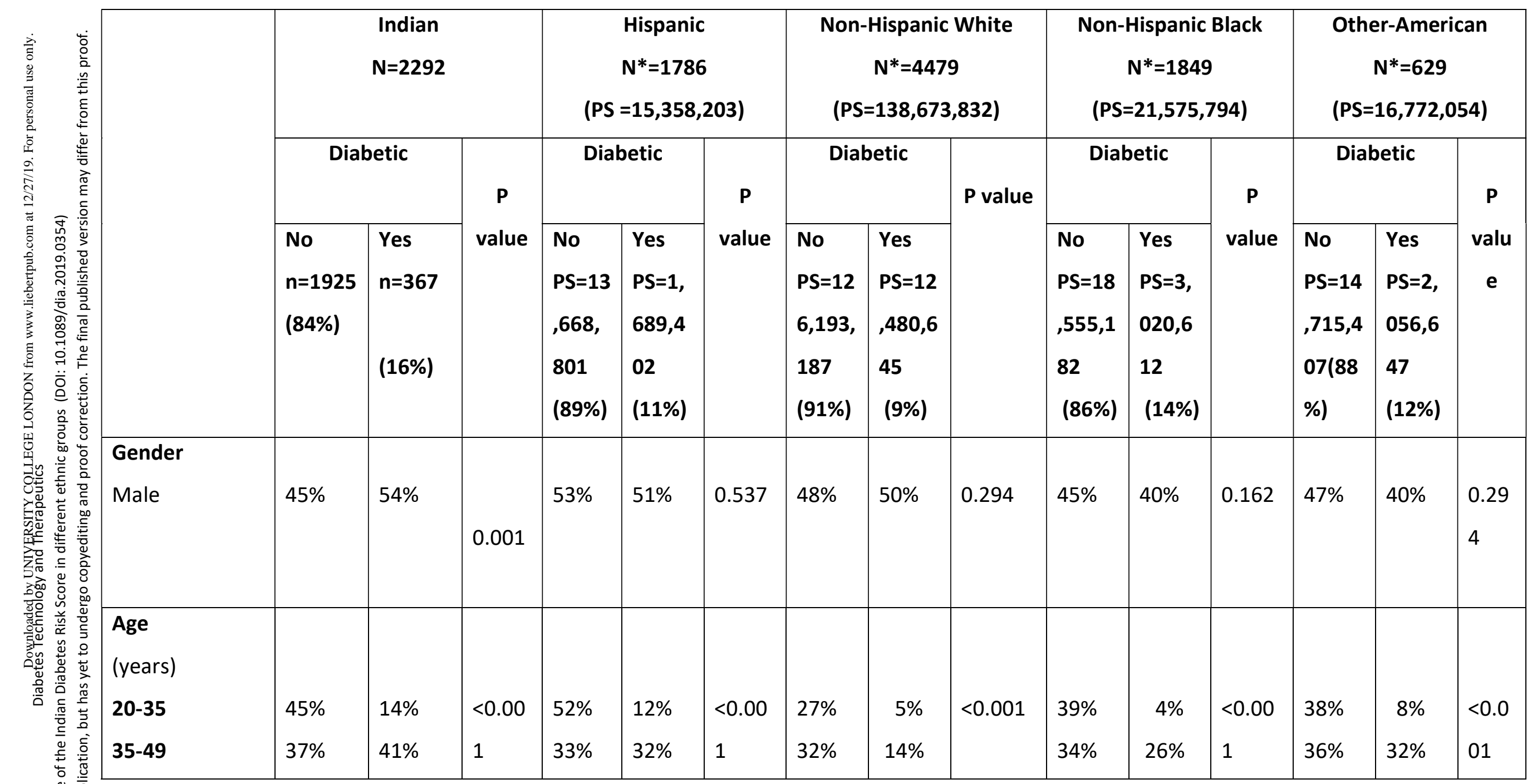




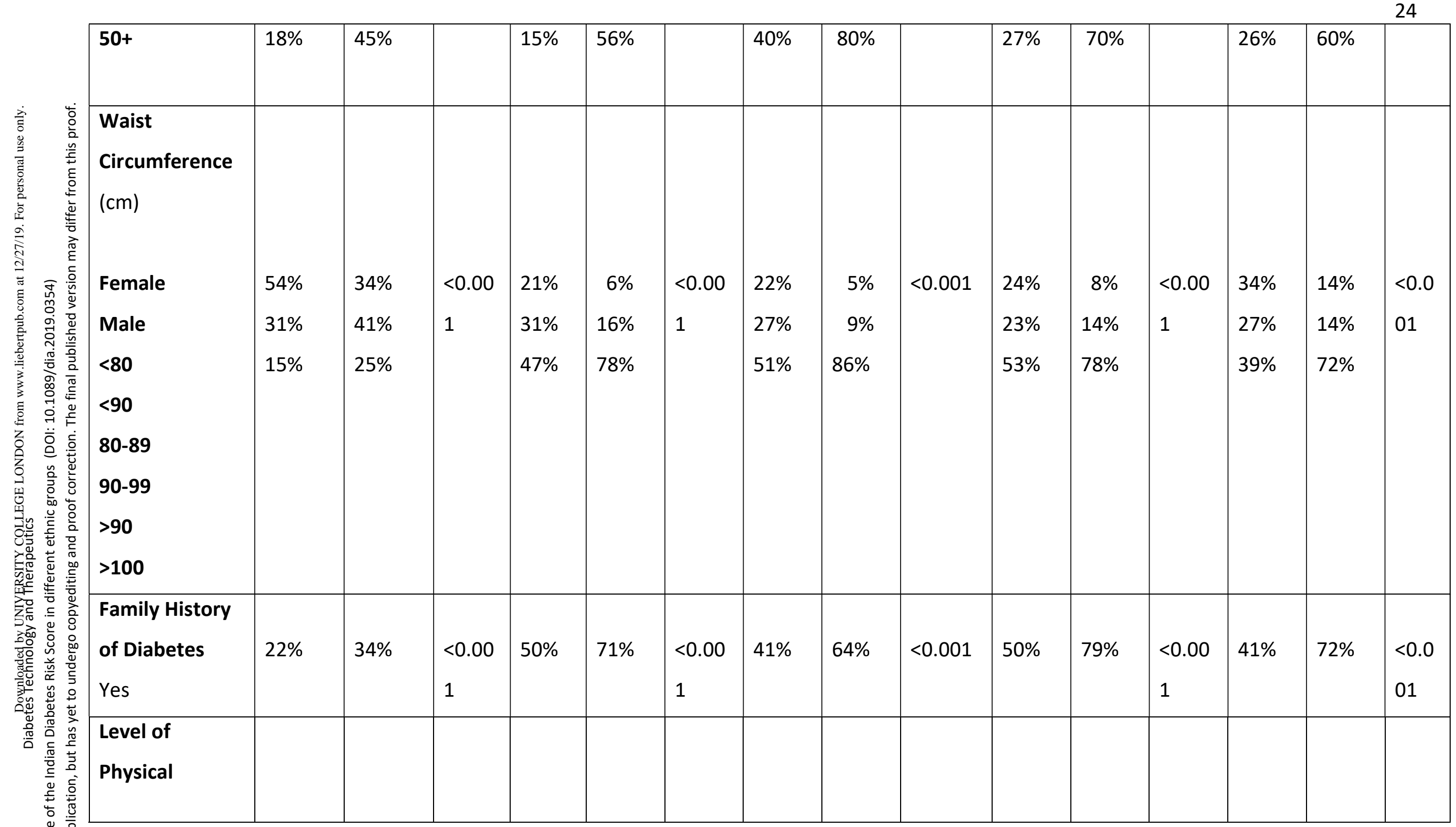




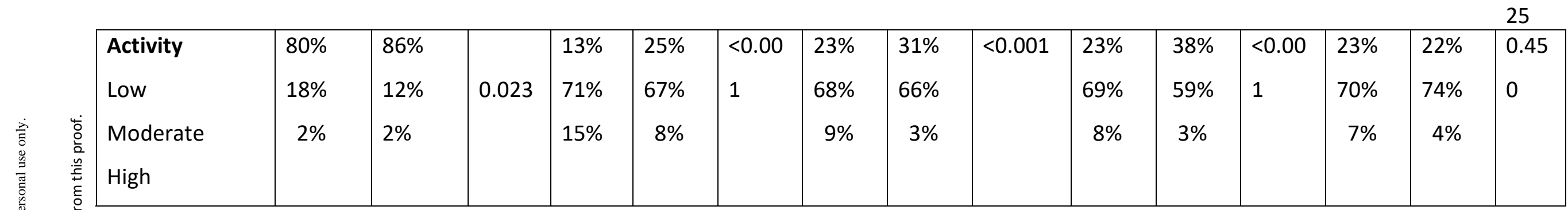

N: CURES dataset total number of individuals sampled using systematic random sampling

$N^{*}$ : NHANES dataset total number of individuals sampled using complex, multistage, probability sampling design

PS: NHANES Survey weight adjusted nationally representative population size

NOTE: The proportions presented for American ethnicities represent the survey weight adjusted proportion out of the population size for each category 
Table 4: Discriminative performance of IDRS score for different ethnicities

\begin{tabular}{|c|c|c|c|c|c|c|c|c|}
\hline Ethnicity & $\begin{array}{l}\text { IDRS cut-off } \\
\text { with highest } \\
\text { performance }\end{array}$ & Sensitivity & Specificity & $\begin{array}{l}\text { Likelihood } \\
\text { ratio of a } \\
\text { positive } \\
\text { test (LR+) }\end{array}$ & $\begin{array}{l}\text { Likelihood } \\
\text { ratio of a } \\
\text { negative } \\
\text { test (LR-) }\end{array}$ & $\begin{array}{l}\text { Youden } \\
\text { Index }\end{array}$ & $\begin{array}{l}\text { Probability } \\
\text { of having } \\
\text { diabetes if } \\
\text { test } \\
\text { positive } \\
\text { (PPV) }\end{array}$ & $\begin{array}{l}\text { Probability } \\
\text { of No } \\
\text { Diabetes if } \\
\text { test } \\
\text { negative } \\
\text { (NPV) }\end{array}$ \\
\hline Indian & 60 & $80.2 \%$ & $57.3 \%$ & 1.88 & 0.34 & 0.37 & 0.26 & 0.94 \\
\hline Hispanic & 70 & $70.1 \%$ & $72.2 \%$ & 2.52 & 0.41 & 0.42 & 0.24 & 0.95 \\
\hline $\begin{array}{l}\text { Non- } \\
\text { Hispanic } \\
\text { White }\end{array}$ & 70 & $86.9 \%$ & $54.8 \%$ & 1.92 & 0.24 & 0.42 & 0.16 & 0.98 \\
\hline $\begin{array}{l}\text { Non- } \\
\text { Hispanic } \\
\text { Black }\end{array}$ & 70 & $86.6 \%$ & $61.2 \%$ & 2.23 & 0.22 & 0.48 & 0.27 & 0.96 \\
\hline $\begin{array}{l}\text { Other- } \\
\text { American }\end{array}$ & 60 & $94.8 \%$ & $48.9 \%$ & 1.85 & 0.11 & 0.44 & 0.21 & 0.98 \\
\hline
\end{tabular}

- $\quad$ IDRS: Indian Diabetes Risk Score

- Youden Index = Sensitivity + Specificity -1 
(Youden Index is a single statistic that captures the performance of a diagnostic test)

- $\quad$ PPV - Positive Predictive Value

- NPV-Negative Predictive Value 
Table 5: Comparison of IDRS Score's performance with non-invasive American diabetes risk score

\begin{tabular}{|l|l|l|}
\hline American Ethnic Groups & $\begin{array}{l}\text { Area Under the Receiver Operating Curve (AUC) in NHANES } \\
\text { Dataset }\end{array}$ & \multicolumn{2}{|l}{ Bang et al Score ${ }^{14}$} \\
\cline { 2 - 3 } & IDRS Score & AUC (95\% CI) \\
\hline Hispanic & AUC (95\% Cl) & $0.8060(0.8056-0.8062)$ \\
\hline Non-Hispanic White & $0.7952(0.7948-0.7955)$ & $0.7990(0.7989-0.7991)$ \\
\hline Non-Hispanic Black & $0.7749(0.7747-0.7750)$ & $0.8221(0.8218-0.8222)$ \\
\hline Other American & $0.8148(0.8145-0.8150)$ & $0.7647(0.7644-0.7650)$ \\
\hline
\end{tabular}

IDRS variables: Age, Waist circumference, Physical activity, Family history of diabetes

Bang et al variables: Age, Gender, Family history of diabetes, self-reported high blood pressure/medication use for hypertension, weight, physical activity level 
Table 6: Performance of IDRS Score in identifying undiagnosed diabetes according to previously published studies in India

\begin{tabular}{|c|c|c|c|c|c|c|c|c|c|}
\hline Paper & Setting & Sample Size (n) & $\begin{array}{l}\text { Age } \\
\text { Group }\end{array}$ & $A \cup C$ & $\begin{array}{l}\text { Cut- } \\
\text { off }\end{array}$ & $\begin{array}{l}\text { Sensitivity } \\
\text { (\%) }\end{array}$ & $\begin{array}{l}\text { Specificity } \\
(\%)\end{array}$ & $\begin{array}{l}\text { PPV } \\
(\%)\end{array}$ & $\begin{array}{l}\text { NPV } \\
\text { (\%) }\end{array}$ \\
\hline $\begin{array}{l}\text { Mohan et al, } \\
2005^{11}\end{array}$ & Chennai & 2350 & $\begin{array}{l}\geq \quad 20 \\
\text { years }\end{array}$ & 0.698 & $\geq 60$ & 72.5 & 60.1 & 17 & 95.1 \\
\hline $\begin{array}{l}\text { Nandeshwar, } \\
2010^{17}\end{array}$ & $\begin{array}{l}\text { Bhopal city, Madhya } \\
\text { Pradesh }\end{array}$ & 250 & $\begin{array}{l}\geq 25 \\
\text { years }\end{array}$ & - & $\geq 60$ & 94.7 & 44.8 & 50.8 & 93.3 \\
\hline $\begin{array}{l}\text { Adhikari et } \\
\text { al, } 2010^{13}\end{array}$ & Mangalore & 551 & $\begin{array}{l}\geq \quad 20 \\
\text { years }\end{array}$ & - & $\geq 60$ & 62.2 & 73.7 & - & - \\
\hline $\begin{array}{l}\text { Patel et al, } \\
2012^{18}\end{array}$ & Bhavnagar city & 260 & $\begin{array}{l}\geq \quad 30 \\
\text { years }\end{array}$ & 0.838 & $\geq 60$ & 92.5 & 62.3 & 30.8 & 97.86 \\
\hline $\begin{array}{l}\text { Stanley et al, } \\
2012^{19}\end{array}$ & Chennai & 154 & $\begin{array}{l}19-99 \\
\text { years }\end{array}$ & - & $\geq 60$ & 100 & 17.6 & - & - \\
\hline $\begin{array}{l}\text { Taksande et } \\
\text { al, } 2012^{20}\end{array}$ & $\begin{array}{l}\text { Rural community of } \\
\text { central India }\end{array}$ & 478 & $\begin{array}{l}\geq \quad 45 \\
\text { years }\end{array}$ & - & $\geq 60$ & 97.5 & 87.89 & - & - \\
\hline $\begin{array}{l}\text { Sathish et al, } \\
2013^{21}\end{array}$ & $\begin{array}{l}\text { Thiruvananthapuram, } \\
\text { Kerala }\end{array}$ & 451 & \begin{tabular}{|l|}
$15 \quad-$ \\
64 \\
years
\end{tabular} & 0.80 & $\geq 60$ & 85.7 & 59.4 & 32.6 & 94.8 \\
\hline Bhadoria et & Jabalpur District & 911 & Adults: & - & $\geq 60$ & 26.4 & 91.7 & 26.1 & 91.8 \\
\hline
\end{tabular}




\begin{tabular}{|c|c|c|c|c|c|c|c|c|c|c|}
\hline al, $2014^{22}$ & & & & $\begin{array}{l}\text { no age } \\
\text { range } \\
\text { given }\end{array}$ & & & & & & \\
\hline $\begin{array}{l}\text { Ahmed et al, } \\
2015^{23}\end{array}$ & Jaipur & 551 & & $\begin{array}{l}\geq 20 \\
\text { years }\end{array}$ & - & $\geq 60$ & 62.2 & 73.7 & - & - \\
\hline $\begin{array}{l}\text { Basu et al, } \\
2015^{27}\end{array}$ & $\begin{array}{l}\text { Nationally } \\
\text { representative } \\
\text { sample of Indians }\end{array}$ & & $\begin{array}{l}567 \\
\text { million } \\
\text { (simulated } \\
\text { sample } \\
\text { using data } \\
\text { from } 58 \\
\text { studies) }\end{array}$ & $\begin{array}{l}25- \\
65 \\
\text { years }\end{array}$ & - & $\geq 60$ & 50.8 & 64.0 & 11.1 & 93.3 \\
\hline $\begin{array}{l}\text { Najeeb et al, } \\
2015^{24}\end{array}$ & Mullana, Ambala & 200 & & $\begin{array}{l}\geq 30 \\
\text { years }\end{array}$ & 0.731 & $\geq 60$ & 65.0 & 62.5 & - & - \\
\hline $\begin{array}{l}\text { Dudeja et al, } \\
2017^{25}\end{array}$ & Urban slum, India & 155 & & $\begin{array}{l}\text { Mean } \\
\text { age: } \\
49.68 \\
\text { SD: } \\
14.80\end{array}$ & - & $\geq 60$ & 95.1 & 28.9 & 32.5 & 94.3 \\
\hline
\end{tabular}




\begin{tabular}{|l|l|l|l|l|l|l|l|l|l|}
\hline $\begin{array}{l}\text { Kaushal et } \\
\text { al, } 2017^{26}\end{array}$ & Shimla & $\begin{array}{l}\geq 65 \\
\text { years }\end{array}$ & - & $\geq 70$ & 61.3 & 56.14 & 23.4 & 86.8 \\
\hline $\begin{array}{l}\text { Oommen et } \\
\text { al, } 2017^{16}\end{array}$ & Tamil Nadu & 4896 & $\begin{array}{l}30-64 \\
\text { years }\end{array}$ & - & - & 59.1 & 59.4 & 8.9 & 95.6 \\
\hline
\end{tabular}

AUC: Area Under the Curve, PPV: Positive Predictive Value, NPV: Negative Predictive Value 
Page 32 of 45

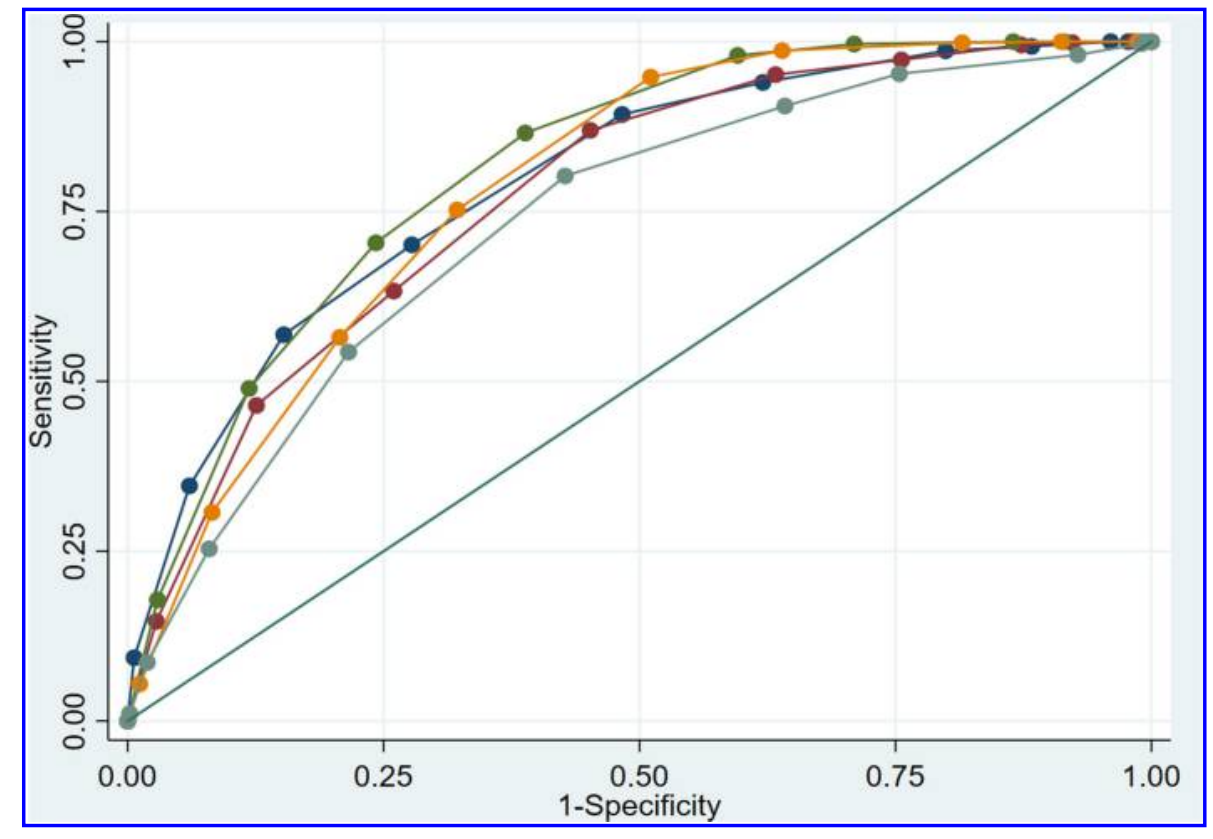

Figure 1: IDRS AUC for different ethnic groups 
Figure 1 Legend

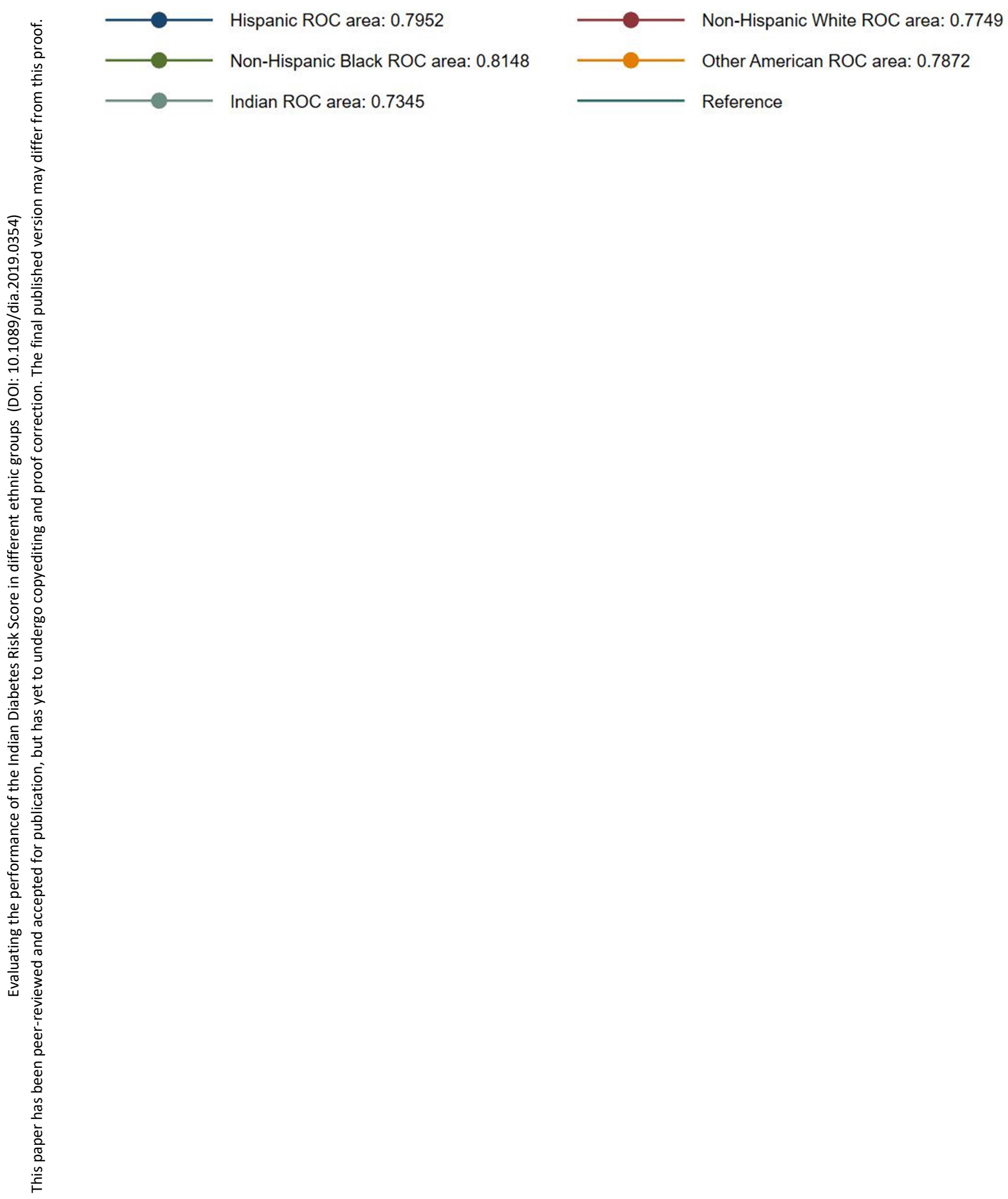




\section{Appendices}

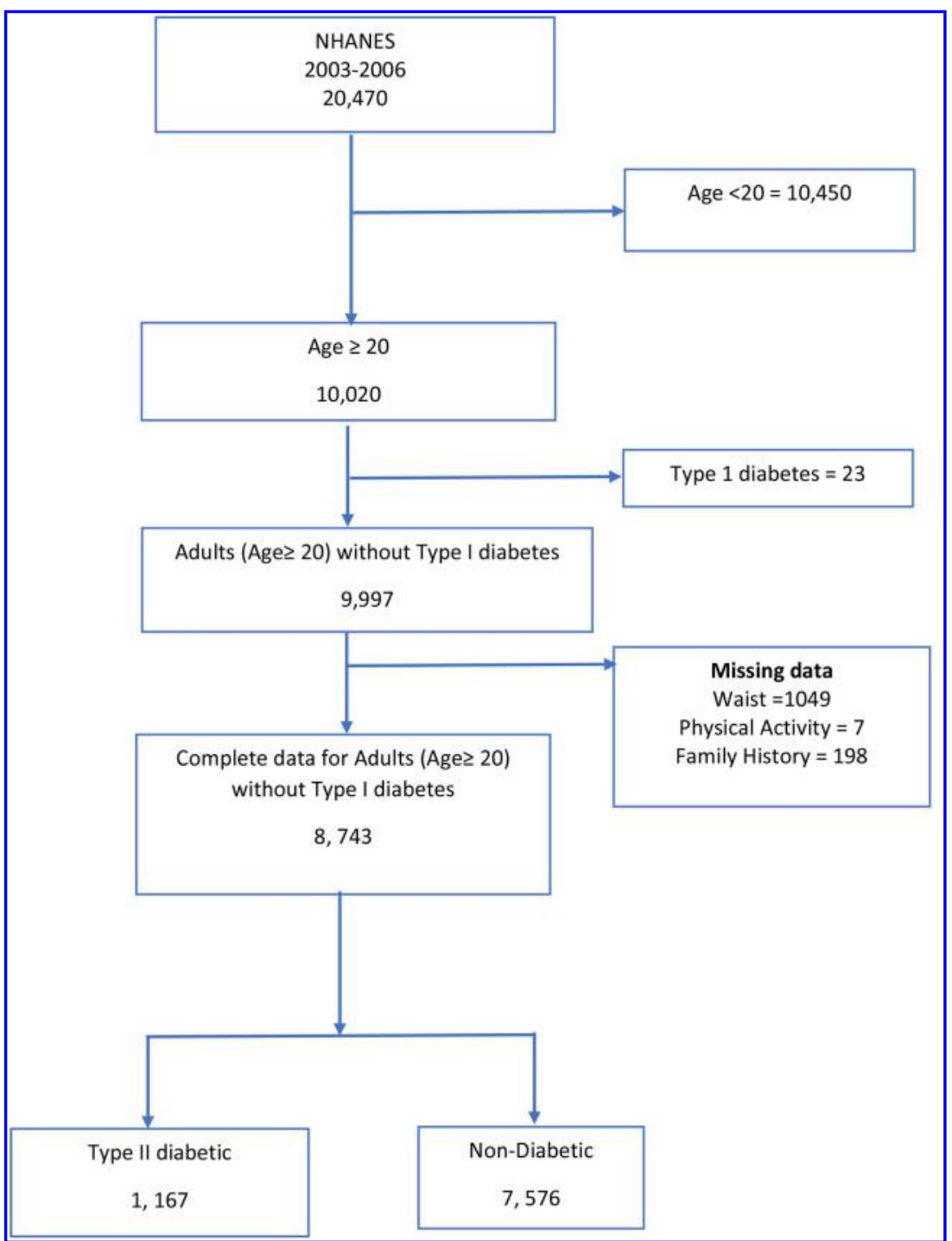

Figure 2: NHANES Data flow chart 


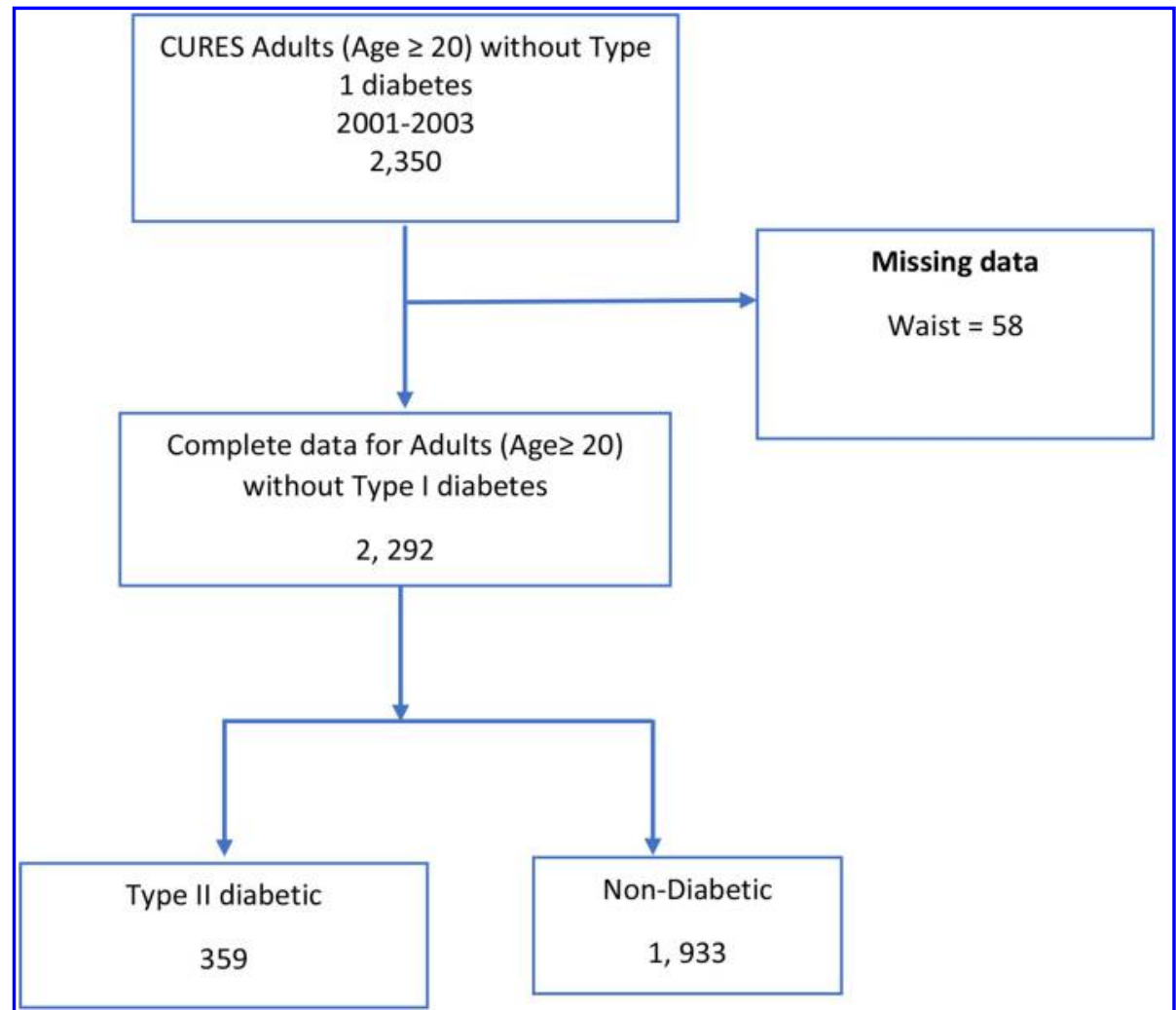

Figure 3: CURES Data flow chart 
Table 5: Optimum cut-off for different ethnic groups

$5(a)$

\section{Indian}

\begin{tabular}{|l|r|r|r|r|l|r|}
\hline Cutpoint & Sensitivity & Specificity & \multicolumn{2}{l|}{$\begin{array}{l}\text { Classified } \\
\text { LR+ }\end{array}$} & \multicolumn{2}{l|}{$\begin{array}{l}\text { ln } \\
\text { Index }\end{array}$} \\
\hline$(>=0)$ & $100.00 \%$ & $0.00 \%$ & $15.66 \%$ & 1 & 0.00 \\
\hline$(>=10)$ & $100.00 \%$ & $0.67 \%$ & $16.23 \%$ & 1.0068 & 0.01 \\
\hline$(>=20)$ & $99.72 \%$ & $0.93 \%$ & $16.40 \%$ & 1.0066 & 0.2991 & 0.01 \\
\hline$(>=30)$ & $98.05 \%$ & $7.19 \%$ & $21.42 \%$ & 1.0565 & 0.2712 & 0.05 \\
\hline$(>=40)$ & $95.26 \%$ & $24.62 \%$ & $35.69 \%$ & 1.2639 & 0.1923 & 0.20 \\
\hline$(>=50)$ & $90.53 \%$ & $35.80 \%$ & $44.37 \%$ & 1.4101 & 0.2646 & 0.26 \\
\hline$(>=60)$ & $80.22 \%$ & $57.27 \%$ & $60.86 \%$ & 1.8774 & 0.3453 & 0.37 \\
\hline$(>=70)$ & $54.32 \%$ & $78.43 \%$ & $74.65 \%$ & 2.5179 & 0.5825 & 0.33 \\
\hline$(>=80)$ & $25.35 \%$ & $92.03 \%$ & $81.59 \%$ & 3.1817 & 0.8111 & 0.17 \\
\hline$(>=90)$ & $8.64 \%$ & $98.09 \%$ & $84.08 \%$ & 4.5113 & 0.9315 & 0.07 \\
\hline$(>=100)$ & $1.11 \%$ & $99.79 \%$ & $84.34 \%$ & 5.3844 & 0.9909 & 0.01 \\
\hline$(>100)$ & $0.00 \%$ & $100.00 \%$ & $84.34 \%$ & & 1 & 0.00 \\
\hline
\end{tabular}


5(b) Hispanic

\begin{tabular}{|c|c|c|c|c|c|c|}
\hline Cutpoint & Sensitivity & Specificity & $\begin{array}{l}\text { Correctly } \\
\text { Classified }\end{array}$ & $\mathrm{LR}+$ & LR- & $\begin{array}{l}\text { Youden } \\
\text { Index }\end{array}$ \\
\hline$(>=0)$ & $100.00 \%$ & $0.00 \%$ & $11.17 \%$ & 1 & & 0.00 \\
\hline$(>=10)$ & $100.00 \%$ & $2.26 \%$ & $13.18 \%$ & 1.0232 & 0 & 0.02 \\
\hline$(>=20)$ & $100.00 \%$ & $3.98 \%$ & $14.71 \%$ & 1.0415 & 0 & 0.04 \\
\hline$(>=30)$ & $99.29 \%$ & $11.70 \%$ & $21.48 \%$ & 1.1245 & 0.0603 & 0.11 \\
\hline$(>=40)$ & $98.66 \%$ & $20.10 \%$ & $28.88 \%$ & 1.2349 & 0.0665 & 0.19 \\
\hline$(>=50)$ & $94.00 \%$ & $37.95 \%$ & $44.22 \%$ & 1.515 & 0.1581 & 0.32 \\
\hline$(>=60)$ & $89.29 \%$ & $51.70 \%$ & $55.90 \%$ & 1.8486 & 0.2072 & 0.41 \\
\hline$(>=70)$ & $70.09 \%$ & $72.24 \%$ & $72.00 \%$ & 2.5247 & 0.414 & 0.42 \\
\hline$(>=80)$ & $56.86 \%$ & $84.74 \%$ & $81.63 \%$ & 3.7265 & 0.5091 & 0.42 \\
\hline$(>=90)$ & $34.62 \%$ & $93.96 \%$ & $87.33 \%$ & 5.7272 & 0.6959 & 0.29 \\
\hline$(>=100)$ & $9.32 \%$ & $99.36 \%$ & $89.30 \%$ & 14.5623 & 0.9126 & 0.09 \\
\hline$(>100)$ & $0.00 \%$ & $100.00 \%$ & $88.83 \%$ & & 1 & 0.00 \\
\hline
\end{tabular}


5(C) Non-Hispanic

White

\begin{tabular}{|l|r|r|r|r|r|r|}
\hline Cutpoint & Sensitivity & Specificity & \multicolumn{2}{l|}{$\begin{array}{l}\text { Classified } \\
\text { LR+ }\end{array}$} & \multicolumn{2}{l|}{$\begin{array}{l}\text { Youden } \\
\text { Index }\end{array}$} \\
\hline$(>=0)$ & $100.00 \%$ & $0.00 \%$ & $10.15 \%$ & 1.0121 & 0 & 0.00 \\
\hline$(>=10)$ & $100.00 \%$ & $1.20 \%$ & $10.60 \%$ & 1.0173 & 0 & 0.02 \\
\hline$(>=20)$ & $100.00 \%$ & $1.70 \%$ & $16.07 \%$ & 1.0821 & 0.0199 & 0.08 \\
\hline$(>=30)$ & $99.85 \%$ & $7.73 \%$ & $20.56 \%$ & 1.1399 & 0.0381 & 0.12 \\
\hline$(>=40)$ & $99.52 \%$ & $12.70 \%$ & $31.02 \%$ & 1.2875 & 0.1103 & 0.22 \\
\hline$(>=50)$ & $97.31 \%$ & $24.42 \%$ & $42.00 \%$ & 1.5033 & 0.1323 & 0.32 \\
\hline$(>=60)$ & $95.14 \%$ & $36.71 \%$ & $57.72 \%$ & 1.924 & 0.2382 & 0.42 \\
\hline$(>=70)$ & $86.95 \%$ & $54.81 \%$ & $73.03 \%$ & 2.4343 & 0.4961 & 0.37 \\
\hline$(>=80)$ & $63.29 \%$ & $74.00 \%$ & $83.71 \%$ & 3.6922 & 0.6125 & 0.34 \\
\hline$(>=90)$ & $46.45 \%$ & $87.42 \%$ & $89.72 \%$ & 5.2336 & 0.8779 & 0.12 \\
\hline$(>=100)$ & $14.67 \%$ & $97.20 \%$ & $90.94 \%$ & & 1 & 0.00 \\
\hline$(>100)$ & $0.00 \%$ & $100.00 \%$ & & & & 12 \\
\hline
\end{tabular}




\section{5(d) Non-Hispanic}

\section{Black}

\begin{tabular}{|l|r|r|r|r|r|r|}
\hline Cutpoint & Sensitivity & Specificity & \multicolumn{2}{l|}{$\begin{array}{l}\text { Classified } \\
\text { LR+ }\end{array}$} & \multicolumn{2}{l|}{$\begin{array}{l}\text { LR- } \\
\text { Index }\end{array}$} \\
\hline$(>=0)$ & $100.00 \%$ & $0.00 \%$ & $14.25 \%$ & 1 & 0.00 \\
\hline$(>=10)$ & $100.00 \%$ & $0.93 \%$ & $15.05 \%$ & 1.0094 & 0.01 \\
\hline$(>=20)$ & $100.00 \%$ & $1.12 \%$ & $15.21 \%$ & 1.0113 & 0 & 0.01 \\
\hline$(>=30)$ & $100.00 \%$ & $8.56 \%$ & $21.60 \%$ & 1.0937 & 0 & 0.09 \\
\hline$(>=40)$ & $100.00 \%$ & $13.51 \%$ & $25.84 \%$ & 1.1562 & 0 & 0.14 \\
\hline$(>=50)$ & $99.65 \%$ & $29.04 \%$ & $39.10 \%$ & 1.4042 & 0.0121 & 0.29 \\
\hline$(>=60)$ & $97.97 \%$ & $40.42 \%$ & $48.62 \%$ & 1.6444 & 0.0502 & 0.38 \\
\hline$(>=70)$ & $86.55 \%$ & $61.17 \%$ & $64.78 \%$ & 2.2287 & 0.2199 & 0.48 \\
\hline$(>=80)$ & $70.39 \%$ & $75.74 \%$ & $74.98 \%$ & 2.9019 & 0.3909 & 0.46 \\
\hline$(>=90)$ & $48.95 \%$ & $88.13 \%$ & $82.55 \%$ & 4.1248 & 0.5792 & 0.37 \\
\hline$(>=100)$ & $17.83 \%$ & $97.08 \%$ & $85.79 \%$ & 6.1105 & 0.8464 & 0.15 \\
\hline$(>100)$ & $0.00 \%$ & $100.00 \%$ & $85.75 \%$ & & 1 & 0.00 \\
\hline
\end{tabular}


5(e) Other

American

\begin{tabular}{|c|c|c|c|c|c|c|}
\hline Cutpoint & Sensitivity & Specificity & $\begin{array}{l}\text { Correctly } \\
\text { Classified }\end{array}$ & LR+ & LR- & $\begin{array}{l}\text { Youden } \\
\text { Index }\end{array}$ \\
\hline$(>=0)$ & $100.00 \%$ & $0.00 \%$ & $12.31 \%$ & 1 & & 0.00 \\
\hline$(>=10)$ & $100.00 \%$ & $1.20 \%$ & $13.35 \%$ & 1.0121 & 0 & 0.01 \\
\hline$(>=20)$ & $100.00 \%$ & $1.34 \%$ & $13.48 \%$ & 1.0136 & 0 & 0.01 \\
\hline$(>=30)$ & $100.00 \%$ & $8.80 \%$ & $20.03 \%$ & 1.0965 & 0 & 0.09 \\
\hline$(>=40)$ & $99.83 \%$ & $18.49 \%$ & $28.50 \%$ & 1.2249 & 0.0091 & 0.18 \\
\hline$(>=50)$ & $98.67 \%$ & $36.08 \%$ & $43.78 \%$ & 1.5436 & 0.0368 & 0.35 \\
\hline$(>=60)$ & $94.79 \%$ & $48.91 \%$ & $54.56 \%$ & 1.8553 & 0.1066 & 0.44 \\
\hline$(>=70)$ & $75.23 \%$ & $67.82 \%$ & $68.73 \%$ & 2.3378 & 0.3652 & 0.43 \\
\hline$(>=80)$ & $56.48 \%$ & $79.27 \%$ & $76.46 \%$ & 2.7242 & 0.5491 & 0.36 \\
\hline$(>=90)$ & $30.71 \%$ & $91.76 \%$ & $84.25 \%$ & 3.7259 & 0.7551 & 0.22 \\
\hline$(>=100)$ & $5.46 \%$ & $98.82 \%$ & $87.34 \%$ & 4.6433 & 0.9567 & 0.04 \\
\hline$(>100)$ & $0.00 \%$ & $100.00 \%$ & $87.69 \%$ & & 1 & 0.00 \\
\hline
\end{tabular}




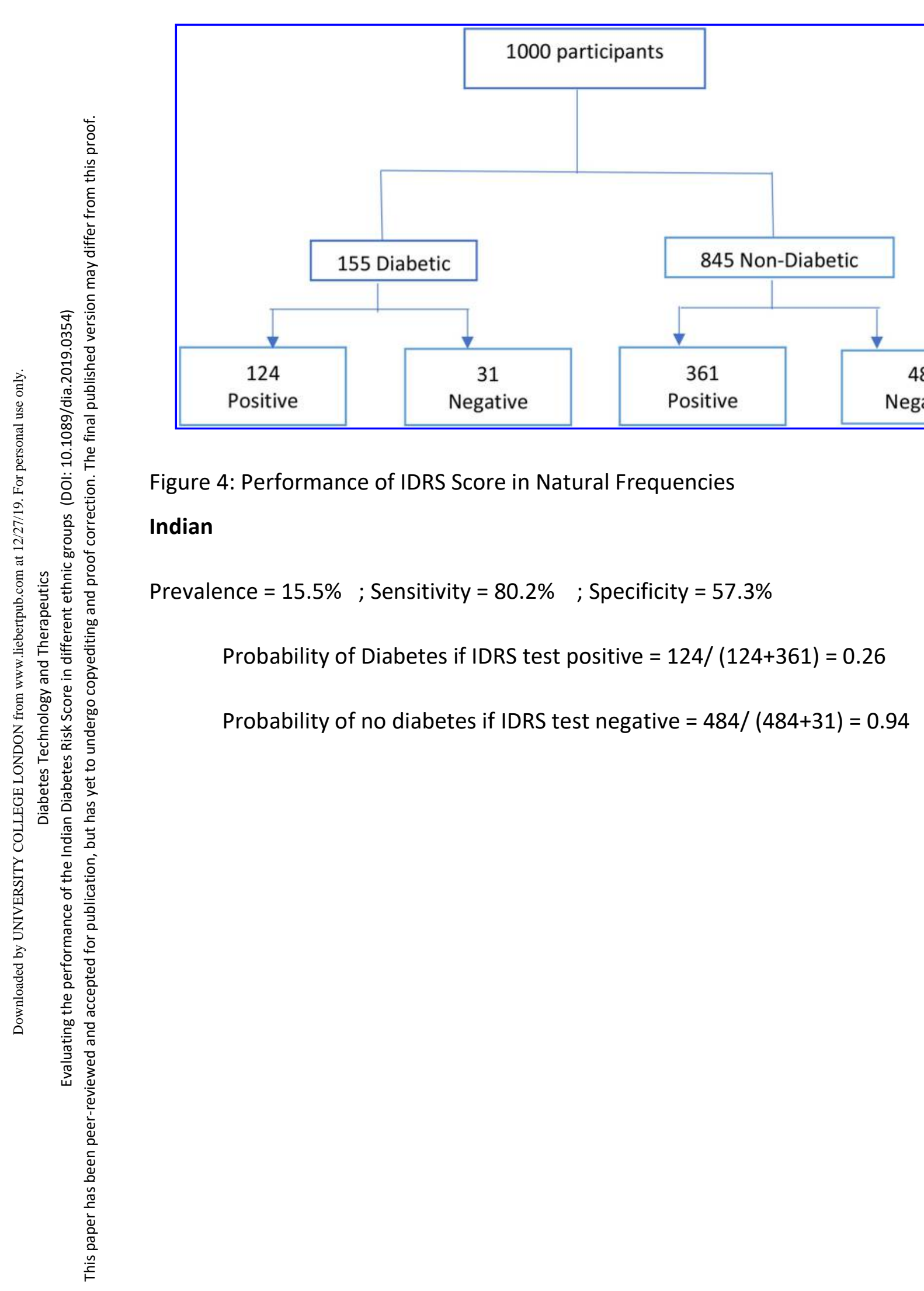




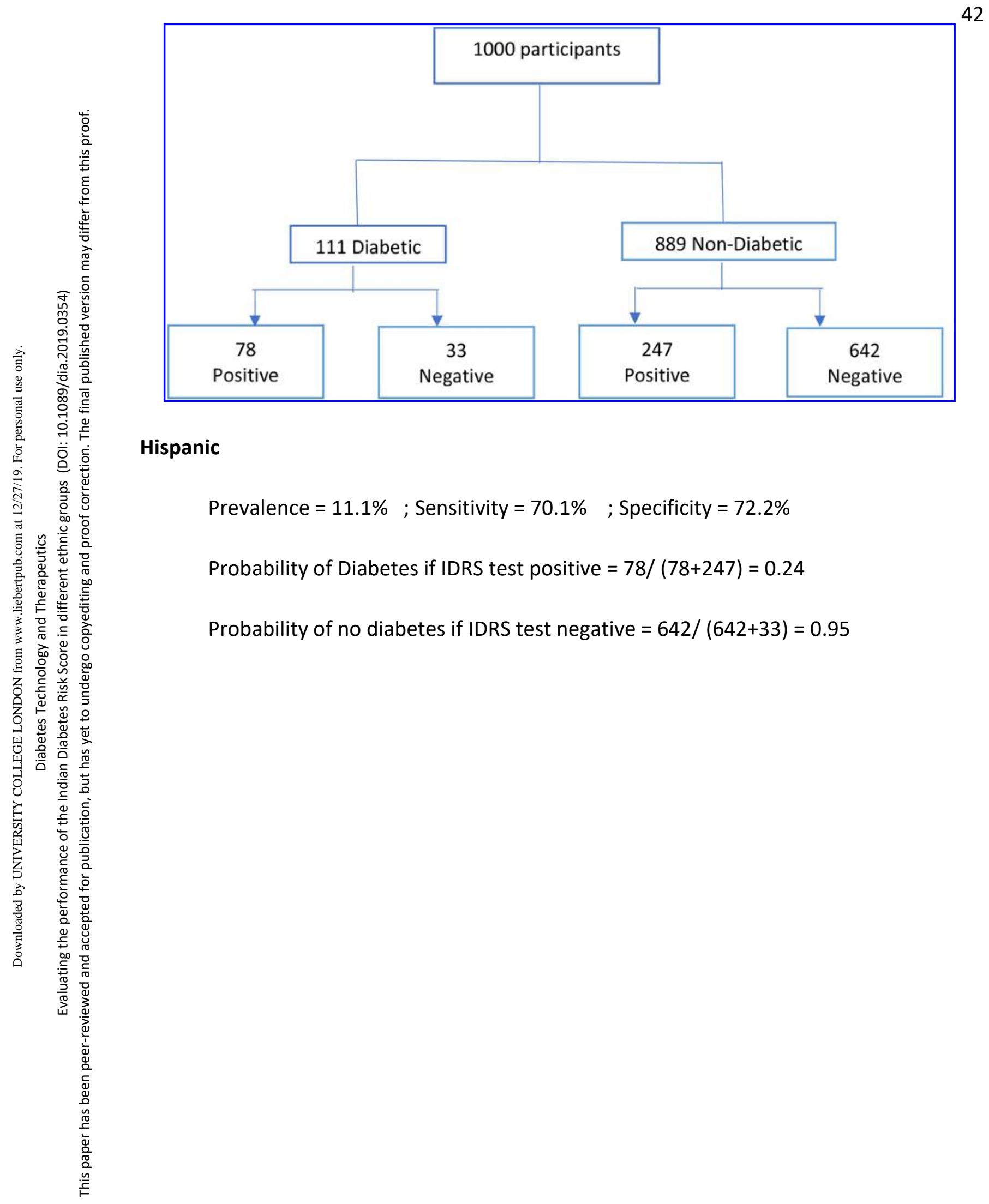




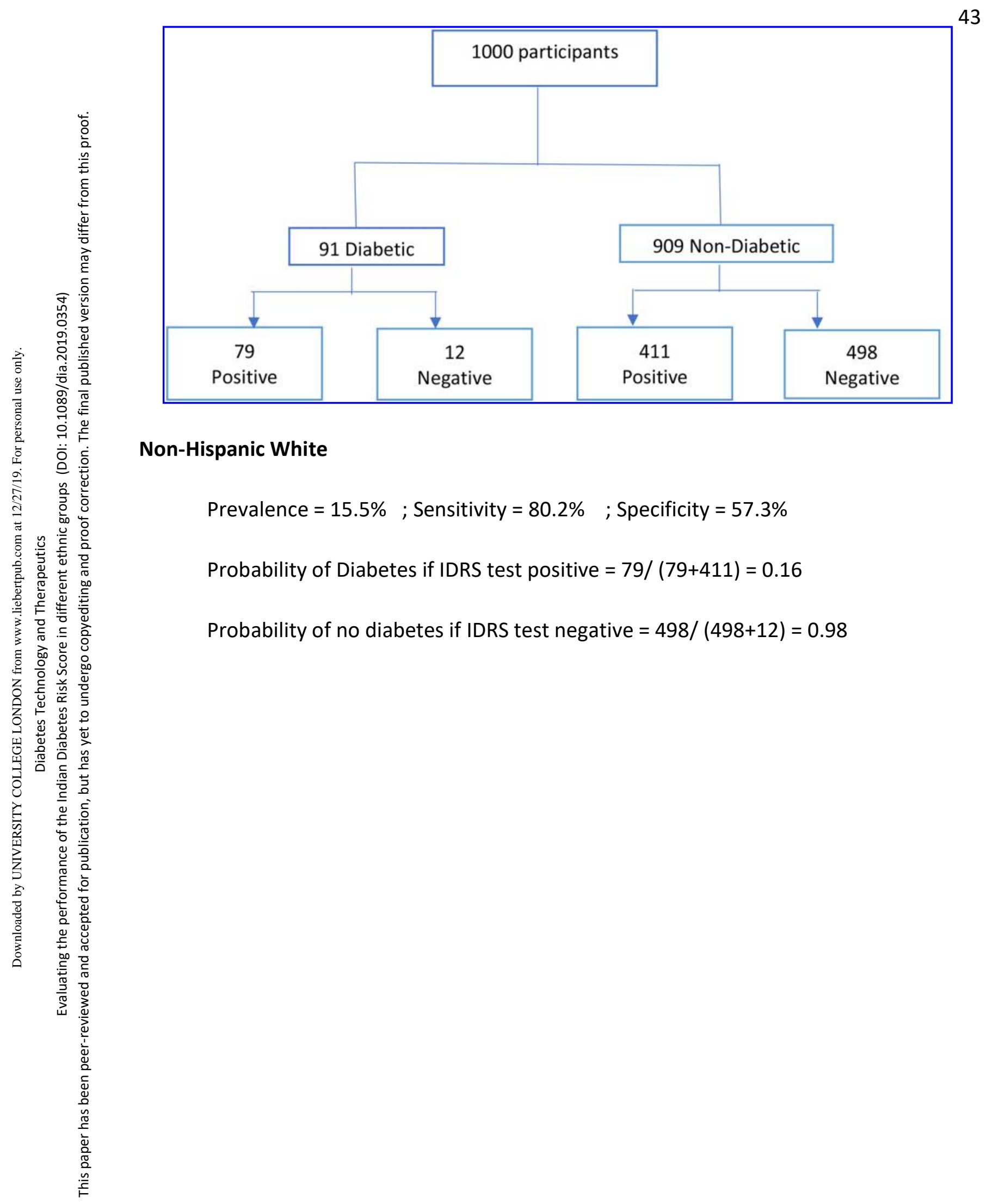




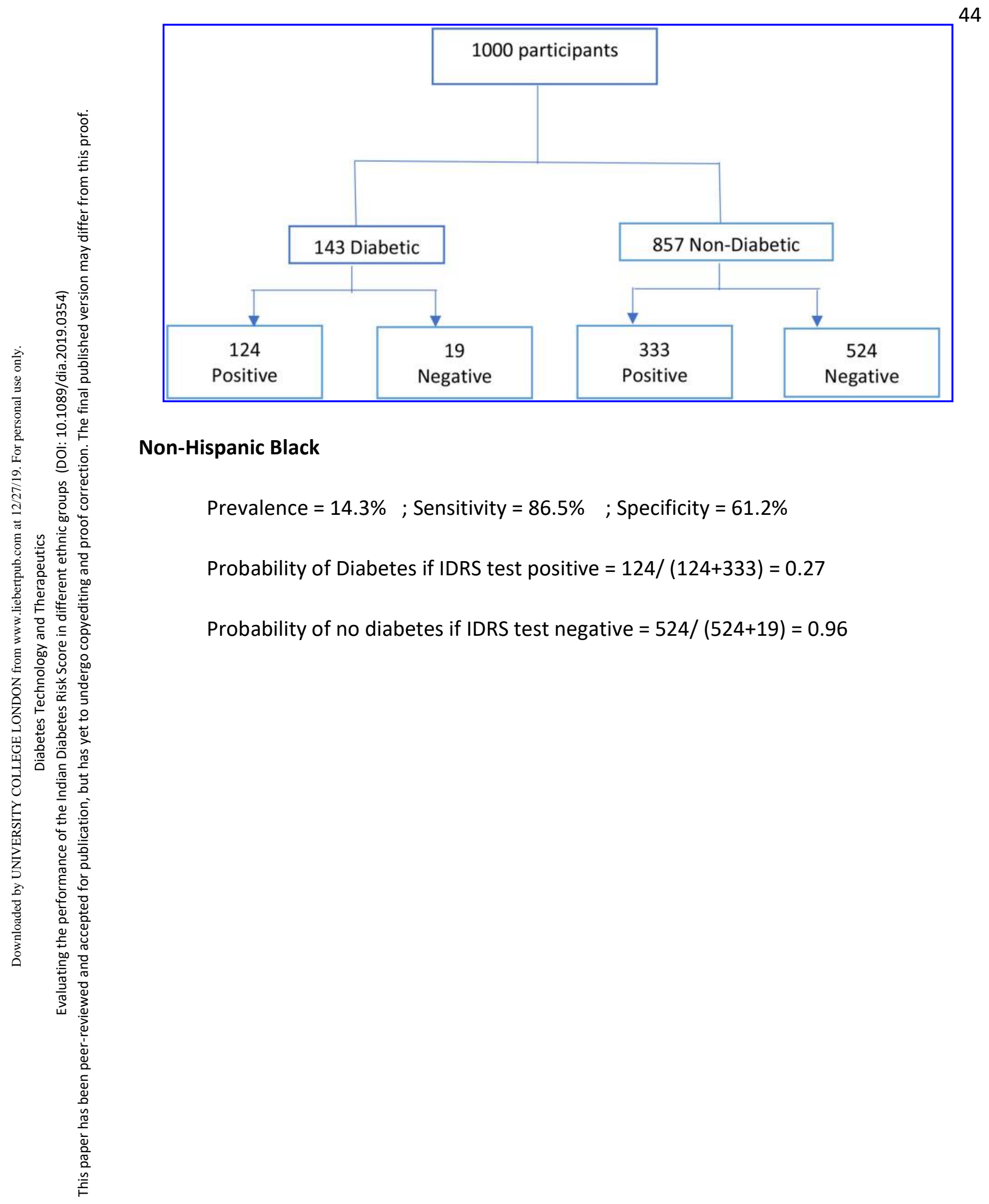




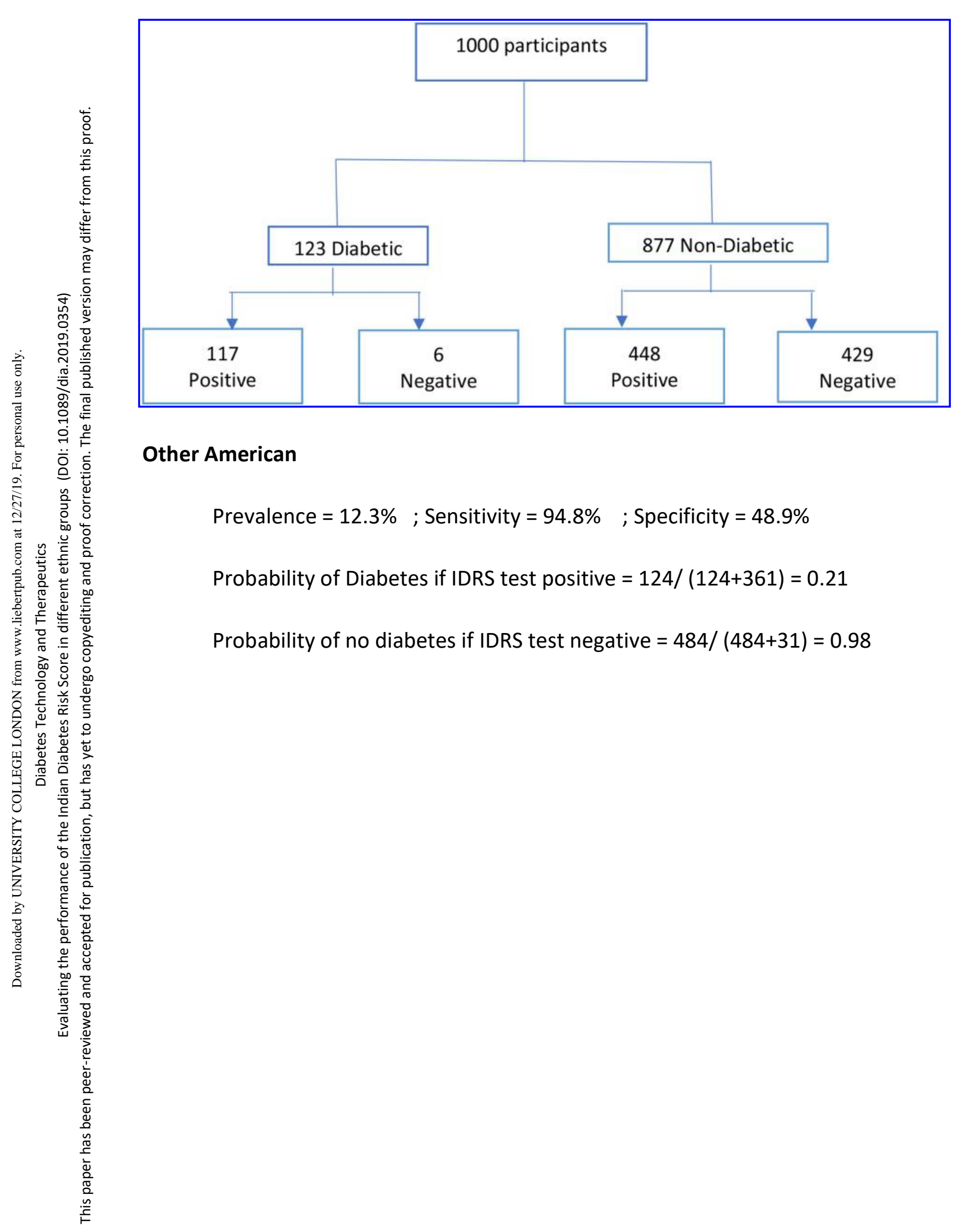

